\title{
Promotion of Ros-mediated Bax/Cyt-c apoptosis by polyphyllin II leads to suppress growth and aggression of glioma cells
}

\author{
Guang Cheng ${ }^{1 \#}$, Yu-Ye Xue ${ }^{2 \#}$, Fei Fang ${ }^{3 \#}$, Guang-Qiang Sun ${ }^{2}$, Yun-Yang Lu ${ }^{4}$, Yu-Qiang Ji ${ }^{3}$, \\ Peng-Cheng Qiu ${ }^{4}$, Hai-Feng Tang ${ }^{4}$
}

${ }^{1}$ Department of Neurosurgery, Xijing Institute of Clinical Neuroscience, Air Force Medical University, Xi'an, China; ${ }^{2}$ School of Pharmacy, Shaanxi University of Chinese Medicine, Xianyang, China; ${ }^{3}$ Central Laboratory of Xi'an No. 1 Hospital, Xi'an, China; ${ }^{4}$ Department of Chinese Materia Medica and Natural Medicines, Key Laboratory of Gastrointestinal Pharmacology of Chinese Materia Medica of the State Administration of Traditional Chinese Medicine, School of Pharmacy, Air Force Medical University, Xi'an, China

Contributions: (I) Conception and design: PC Qiu, HF Tang; (II) Administrative support: HF Tang; (III) Provision of study materials or patients: None; (IV) Collection and assembly of data: G Cheng, YY Xue, F Fang; (V) Data analysis and interpretation: GQ Sun, YY Lu, YQ Ji; (VI) Manuscript writing: All authors; (VII) Final approval of manuscript: All authors.

\#These authors contributed equally to this work.

Correspondence to: Peng-Cheng Qiu; Hai-Feng Tang. Department of Chinese Materia Medica and Natural Medicines, Key Laboratory of Gastrointestinal Pharmacology of Chinese Materia Medica of the State Administration of Traditional Chinese Medicine, School of Pharmacy, Air Force Medical University, Xi'an 710032, China. Email: qpc023@126.com; tanghaifeng71@163.com.

Background: Gliomas remain among the most difficult cancers to treat, with a 5-year overall survival no greater than $5 \%$. Many saponins showed a wide spectrum of anti-cancer activities at low concentration. Polyphyllin II is one of the common saponins from Paris polyphylla. However, the effect of Polyphyllin II on glioma cells has not been evaluated. Objective of the present study was to investigate whether Polyphyllin II have inhibition on glioma cells, and the possible mechanisms.

Methods: The viability of U87 and U251 cells was detected by cell counting kit-8, cell counting real time cellular analysis and cell clone formation methods. Transwell was used to estimate the aggression of U87 and U251. The cell apoptosis rate was tested by flow cytometry. The morphological change was determined by transmission electron microscopy. The levels of AKT, phosphorylation of AKT, Bax, Bcl-2, cytochrome c, and cleaved caspase 3 proteins were assessed by Western blot. $\mathrm{N}$-acetyl-L-cysteine was used to check the role of ROS in polyphyllin II inhibition to glioma cells.

Results: Polyphyllin II showed significant suppress to proliferation and aggression of U87 and U251 in a dose- and time- dependent manner. Result of flow cytometry confirmed that Polyphyllin II induced apoptosis to U87 and U251 cells. Transmission electron microscopy observation revealed majority of the glioma cells treated with Polyphyllin II had turgidity of mitochondrion, disarrangement, diminution and vacuolization, those refer to mitochondrial apoptosis. Western blot indicated that Polyphyllin II promoted cyt-c, Bax, caspase 3 and cleaved-caspase 3, and decreased Bcl-2, AKT and p-AKT. Rescue experiments using N-acetylL-cysteine, a reactive oxygen species scavenger, reversed the levels of Bax and cyt-c, and the inhibition in Polyphyllin II-treated U87 and U251 cells.

Conclusions: The present findings revealed that polyphyllin II may be a potential drug against glioma.

Keywords: Cancer; saponin; mitochondrial apoptosis; reactive oxygen species; Paris polyphylla

Submitted Jun 03, 2021. Accepted for publication Aug 14, 2021.

doi: $10.21037 /$ tcr-21-966

View this article at: https://dx.doi.org/10.21037/tcr-21-966

\footnotetext{
$\wedge$ ORCID: 0000-0002-4826-4094.
} 


\section{Introduction}

In the central nervous system glioma is one of the most common primary tumors, and almost half of glioma is glioblastoma, that is associated with 5-year relative survival not more than $5 \%$ (1-3). Therefore, discovery of new drugs for anti-glioma is continued to be meaningful. Natural products have significantly contributed to the discovery of new compounds for new anti-cancer drugs. Saponins as a kind of important natural products have the characteristics of outstanding pharmacological effects, such as antiinflammatory, antiviral, immune regulatory, cardiovascular protection (4-7) and anti-tumor activities $(8,9)$. Many saponins showed a wide spectrum of anti-tumor activities at low concentration. Including our previous work, anticancer saponins were isolated from Anemone tomentosa (10), Clematis argentilucida (11), Anemone taipaiensis (12-15), Ardisia pusilla $(16,17)$, starfish Culcita novaeguineae $(18,19)$, and sea cucumbers (20-22). But the yield of many anticancer saponins isolation is low.

Paris polyphylla is extensively used in traditional system of Chinese medicine and widely distributed in China (23). Clinically and traditionally, Paris polyphylla is used as an analgesic, anti-inflammatory (9) and hemostatic medical herb (24) and shows anti-cancer effects in various cancer types (25-28). Secondary metabolites such as daucosterol, polyphyllin D, $\beta$-ecdysterone, polyphyllin I, II, V, VI, VII, H, dioscin, oligosaccharides, heptasaccharide, octasaccharide, trigofoenoside A, protogracillin, Paris yunnanosides G-J, padelaoside B, pinnatasterone, formosanin $\mathrm{C}$ and 20-hydroxyecdyson saponins have been isolated from Paris polyphylla (23). A series of saponins from Paris polyphylla have better drug accessibility and have been reported anti-cancer effects. Such as polyphyllin I $\left(\mathrm{C}_{44} \mathrm{H}_{70} \mathrm{O}_{16}\right)(29,30)$, II $\left(\mathrm{C}_{51} \mathrm{H}_{82} \mathrm{O}_{20}\right)(31,32)$ and VII $\left(\mathrm{C}_{51} \mathrm{H}_{82} \mathrm{O}_{21}\right)$ (33-37): according to Chinese Pharmacopoeia 2020 edition the total content of polyphyllin $\mathrm{I}\left(\mathrm{C}_{44} \mathrm{H}_{70} \mathrm{O}_{16}\right)$, II $\left(\mathrm{C}_{51} \mathrm{H}_{82} \mathrm{O}_{20}\right)$ and VII $\left(\mathrm{C}_{51} \mathrm{H}_{82} \mathrm{O}_{21}\right)$ should not be less than $0.60 \%$ in dried Paris polyphylla rhizome (38). Nevertheless, on glioma we still know little about the effect and apoptosis mechanism of Polyphyllin II (PPII). In this study, the effect and underlying mechanism of PPII on U87 and U251 cells were evaluated by RTCA, CCK-8, clone formation, transwell, transmission electron microscopy (TEM), western blot and flow cytometry. U87 cells are wild-type p53 glioma cells and U251 cells contain mutant p53 (39).

The present study aimed to evaluate the role of PPII in the regulation of apoptosis in glioma cells, and to identify the potential underlying mechanisms. The results revealed PPII significantly suppressed the vitality and aggression of U87 and U251 cells in a dose- and time-dependent manner via $\mathrm{AKT} / \mathrm{p}-\mathrm{AKT} / \mathrm{Bax} / \mathrm{Bcl}-2 /$ cyt-c/caspase 3/cleaved-caspase 3 pathway. Rescue experiments confirmed PPII inhabited the proliferation via ROS-mediated Bax/cyt-c in glioma. The present findings revealed that PPII may be a potential drug against glioma.

We present the following article in accordance with the MDAR reporting checklist (available at https://dx.doi. org/10.21037/tcr-21-966).

\section{Methods}

\section{Cell culture}

Human glioma cell lines U87 (catalog number: TCHu138) and U251 (catalog number: TCHu 58) were bought from the Cell Bank of Chinese Academy of Science (Shanghai, China). The cell lines were cultured in DMEM (Gibco, China) supplemented with 10\% FBS (Ausbian, Harbin, China) and maintained at $37^{\circ} \mathrm{C}$ with $5 \% \mathrm{CO}_{2}$.

\section{Cell proliferation assay}

The logarithmic phase cells $\left(5 \times 10^{3}\right.$ cells/well $)$ were seeded in 96-well-plate, and $24 \mathrm{~h}$ later the cells were incubated with different doses of PPII for $24 \mathrm{~h}$, four replicated wells were used for each experimental condition. $10 \mu \mathrm{L}$ CCK-8 was added to each well (incubated at $37^{\circ} \mathrm{C}$ for $2 \mathrm{~h}$ ) for the measurement of the cell proliferation using a microplate reader $(450 \mathrm{~nm})$.

\section{Clone formation}

Cells were seeded in a fresh six-well plate and maintained in media containing $10 \%$ FBS, replacing the medium every 4 days. After 14 days, methanol and stained with $0.1 \%$ crystal violet (ACROS organics) fixed cells.

\section{Transwell}

Inserts of transwell flat bottom plate were coated with/ without polylysine for invasion/migration (BD Bioscience, San Jose, CA, USA). $2 \times 10^{5}$ cells with $300 \mu \mathrm{L}$ Serum-free medium were seeded to the upper chamber. In the lower chamber, $500 \mu \mathrm{L}$ of medium (10\% FBS) was added. After $24 \mathrm{~h}$, the cells that did not migrate through the pores (upper 
surface) were removed by scraping the membrane with a cotton swab. The cells were fixed in $4 \%$ paraformaldehyde for 15 to $30 \mathrm{~min}$ in the membrane. After fixed, the cells continued to be stained for 10 to 20 min with $0.1 \%$ crystal violet.

\section{Flow cytometric analysis}

$2 \times 10^{5}$ cells were treated with different doses of PPII. After $24 \mathrm{~h}$, the cells were washed with cold PBS $\left(4^{\circ} \mathrm{C}\right)$. The cells apoptosis rates were tested by Annexin V Apoptosis Detection Kit I. The result was evaluated by a flow cytometer (BD Bioscience) after the cells were labeled with Annexin-V and PI.

\section{Transmission electron microscopy analysis}

Cells were After $2 \mathrm{~h}$ fixed in 2\% glutaraldehyde, the cells were washed with PBS for 10 min twice, and then were fixed in $1 \% \mathrm{OsO}_{4}$. Samples were cut and analyzed with a JEM-1400 (JEM-1400, JEOL, Japan).

\section{Real time cellular analysis (RTCA)}

$1 \times 10^{4}$ cells with $200 \mu \mathrm{L}$ were seeded in E-plates at $37^{\circ} \mathrm{C}$ and $5 \% \mathrm{CO}_{2}$ for $120 \mathrm{~h}$ recorded by iCELLigence system (ACEA Biosciences, Inc., San Diego, CA, USA).

\section{Western blot analysis}

Cells were treated with different doses of PPII $(1.85 \mu \mathrm{g} / \mathrm{mL}$ for U87, $5 \mu \mathrm{g} / \mathrm{mL}$ for U251) for $24 \mathrm{~h}$, and washed twice in cold PBS. Then the treated cells were collected and lysed in RIPA lysis buffer, bicinchoninic acid (BCA) kit was used to determine protein concentration, all the protein samples were quantified to be the same concentration. Cell lysates $(50 \mu \mathrm{g})$ were subjected to sodium dodecyl sulfate (SDS)polyacrylamide gel electrophoresis (PAGE) and transferred onto polyvinylidene difluoride (PVDF) membrane. Then incubated with the primary antibody at $4{ }^{\circ} \mathrm{C}$ overnight after blocked with $5 \%$ non-fat dry milk, and then incubated again with the secondary antibody in a dark place for $1 \mathrm{~h}$. The protein level was corrected using glyceraldehyde-3phosphate dehydrogenase (GAPDH). P-AKT (Affinity Biosciences, Inc., USA, product code: AF0908), AKT (Servicebio Inc., China, product code: GB13427), BAX (Servicebio Inc., China, product code: GB11690), caspase 3 (Servicebio Inc., China, product code: GB11767C), cleaved-caspase 3 (Servicebio Inc., China, product code: GB11009), cytochrome C (Servicebio Inc., China, product code: GB11080), BCL2 (Wanleibio Co, China, product code: WL0234), GAPDH (Santa Cruz Biotechnology, Inc., USA, product code: sc-32233).

\section{Statistical analysis}

Experiments were performed in biological replicates and randomly divided to treatments or untreatments, most of which included at minimum technical triplicates $(n=3)$, as indicated in the figure legends. Sample size depended on the assay type. The investigators were blinded to the group allocation during the experiment when assessing the outcome of CCK-8, cell clone formation, RTCA, transwell, western blot, TEM, and flow cytometer detection. Means were compared with one-way analysis of variance or two-way analysis of variance when applicable. Multiple comparisons were performed by Tukey's multiple comparisons test. All data are analyzed using GraphPad Prism. A value of $\mathrm{P}<0.05$ was considered as statistically significant difference.

The study was conducted in accordance with the Declaration of Helsinki (as revised in 2013).

\section{Results}

\section{PPII inbibited glioma cell proliferation, migration and invasion in a dose-and time-dependent manner}

To test the effect of PPII (Figure 1A) on glioma cell growth, proliferation assay was done in U87 and U251 cells treated with different doses of PPII (20, 10, 5, 2.5, 1.25, 0.625, 0.3125, and $0.15625 \mu \mathrm{g} / \mathrm{mL}$ ) for $24 \mathrm{~h}$. We used CCK-8 assay to detect the cell viability and the results showed PPII decreased the OD values of U87 and U251 in a dose-dependent manner compared with the control group (Figure $1 \mathrm{~B}$ ). The $\mathrm{IC}_{50}$ values of the saponin against the proliferation of U87 and U251 cells were $3.695 \mu \mathrm{g} / \mathrm{mL}$ and $10.04 \mu \mathrm{g} / \mathrm{mL}$ (Figure $1 C$ ). According to the $\mathrm{IC}_{50}$ values, $3.7 \mu \mathrm{g} / \mathrm{mL}$ PPII was used as high dose, and $1.85 \mu \mathrm{g} / \mathrm{mL}$ PPII was used as low dose in U87 cells; $10 \mu \mathrm{g} / \mathrm{mL}$ PPII was used as high dose, and $5 \mu \mathrm{g} / \mathrm{mL}$ PPII was used as low dose in U251 cells. To verify the inhibition of PPII on glioma cell growth, proliferation was measured by iCELLigence and cell clone formation. iCELLigence is a real time monitoring system for an overall detection of the cells proliferation. The result showed that both of high and low doses could inhibit the 
A

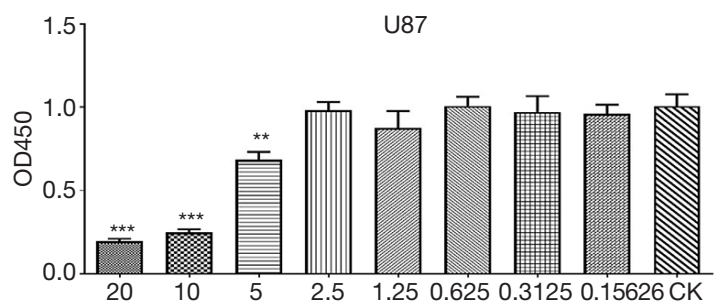

B

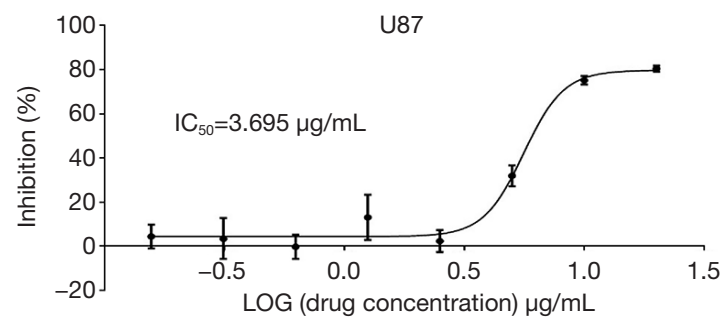

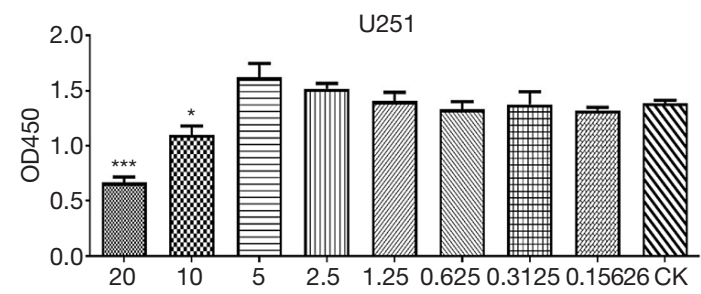

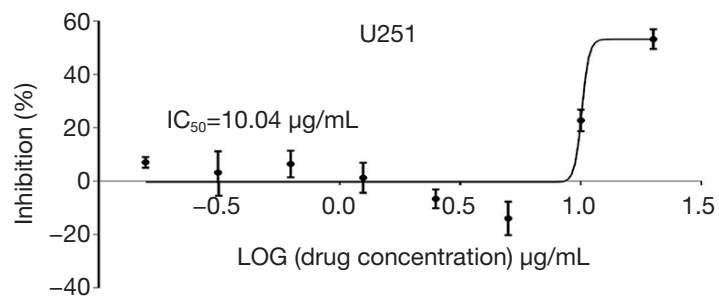

C
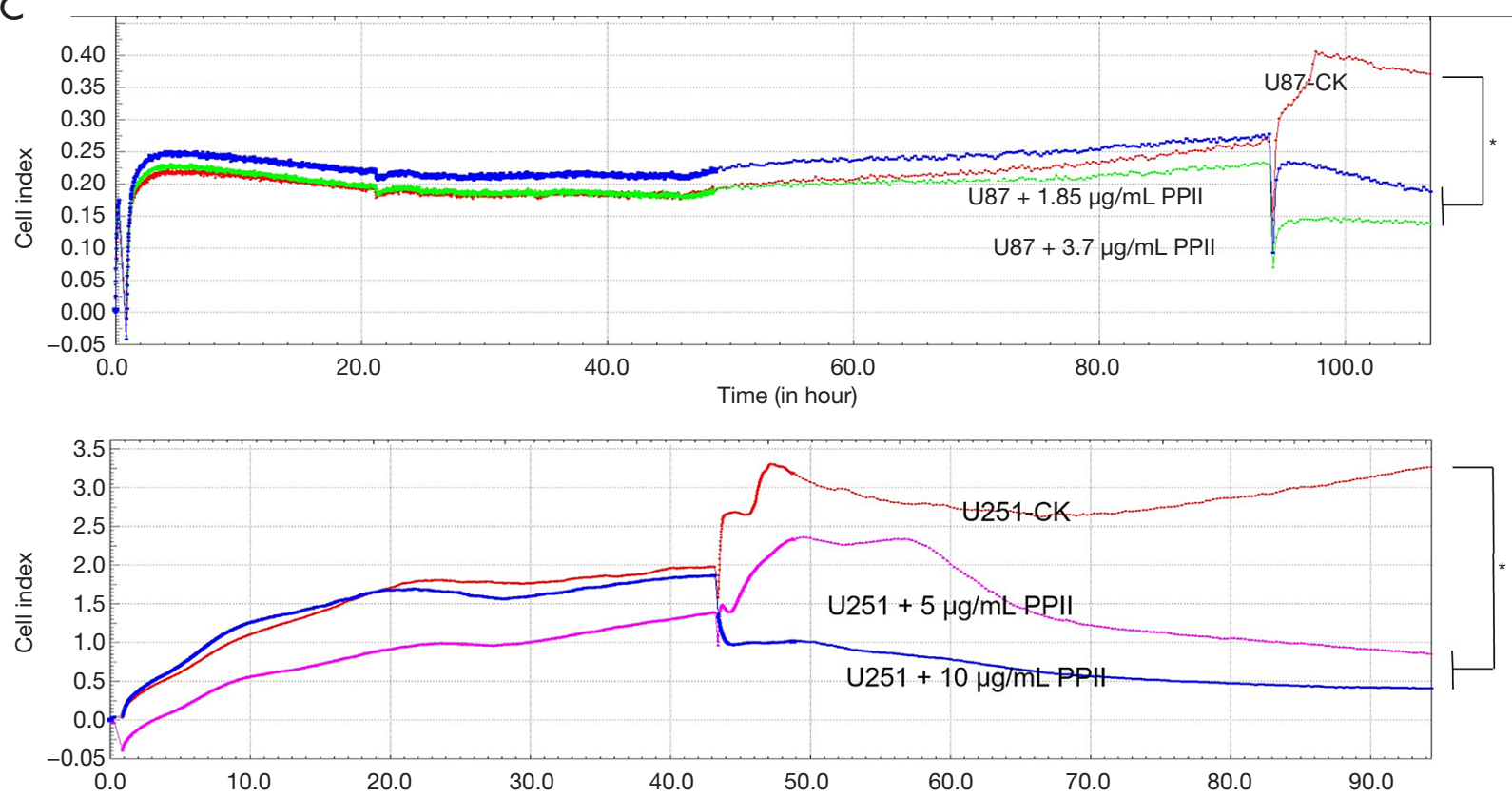

Figure 1 Low concentration of PPII inhibited glioma cell proliferation. (A) Structure of PPII. (B) PPII inhibited proliferation of U87 and U251 cells in a dose-dependent manner ( $\mathrm{n}=4,24 \mathrm{~h},{ }^{*}, \mathrm{P}<0.05$; ${ }^{* *}, \mathrm{P}<0.01$; ${ }^{* *}, \mathrm{P}<0.001$ compared with normal glioma cells). (C) $\mathrm{IC}_{50}$ value of $3.695 \mu \mathrm{g} / \mathrm{mL}$ PPII for U87 cells and $\mathrm{IC}_{50}$ value of $10.04 \mu \mathrm{g} / \mathrm{mL}$ PPII for U251 cells ( $\mathrm{n}=4,24 \mathrm{~h}$ ); (D) iCELLigence showed PPII inhibited proliferation of U87 and U251 cells in a dose- and time-dependent manner ( $\mathrm{n}=3,{ }^{*}, \mathrm{P}<0.05$ compared with normal glioma cells). PPII, polyphyllin II.

glioma cells proliferation in a time-dependent manner with PPII treatment (Figure 1D). Cell clone formation provided intuitive pictures that PPII inhibited glioma cell proliferation in a dose-dependent manner (Figure $2 A$ ). So did transwell test and the results revealed both of high and low doses of PPII inhibited migration and invasion of the glioma cells (Figure 2B).

\section{PPII induced apoptosis to glioma cells}

The above results confirmed that low concentration of PPII could inhibit glioma cell proliferation. The next question is what the mechanism is. Often apoptosis contributes to proliferation inhibition in drug anti-cancer. In order to determine the relationship between PPII and glioma cell 


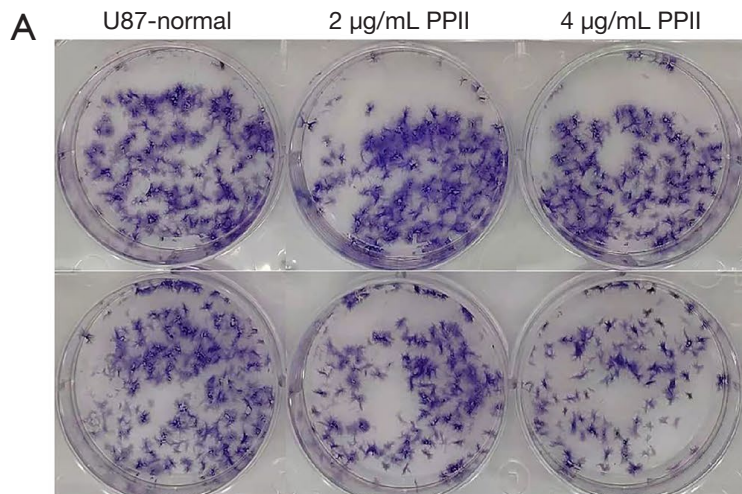

$6 \mu \mathrm{g} / \mathrm{mL}$ PPII
$8 \mu \mathrm{g} / \mathrm{mL}$ PPII
$10 \mu \mathrm{g} / \mathrm{mL}$ PPII

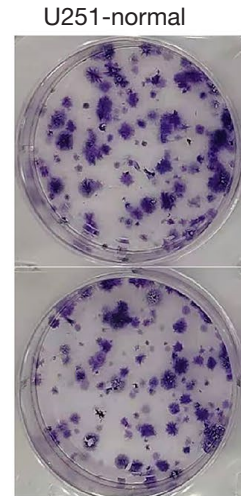

$6 \mu \mathrm{g} / \mathrm{mL}$ PPII
$1.5 \mu \mathrm{g} / \mathrm{mL}$ PPII

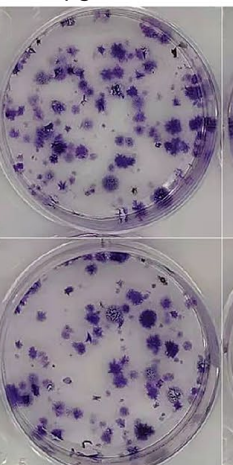

$9 \mu \mathrm{g} / \mathrm{mL}$ PPII
$3 \mu \mathrm{g} / \mathrm{mL}$ PPII

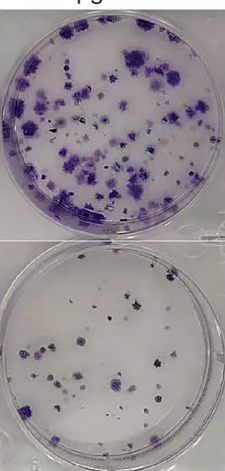

$12 \mu \mathrm{g} / \mathrm{mL}$ PPII
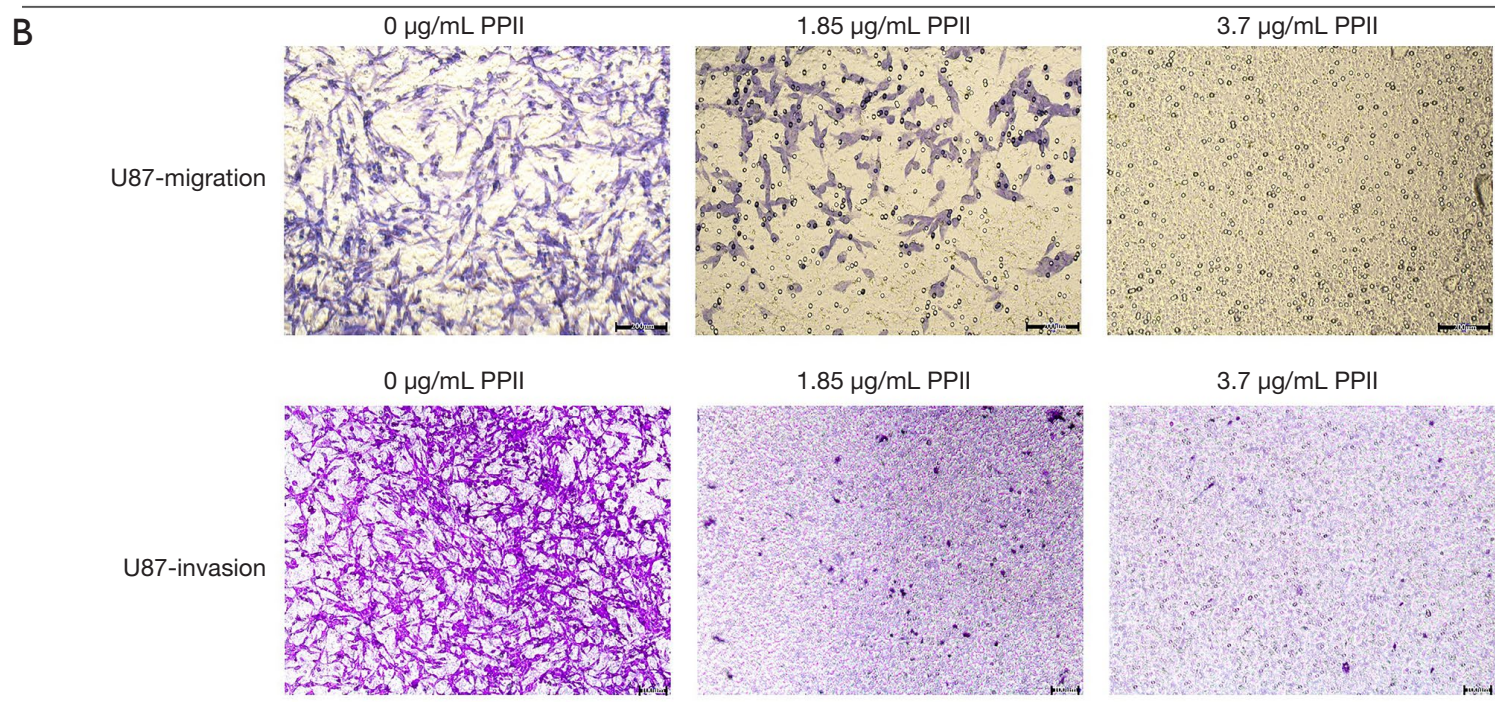

\section{$3.7 \mu \mathrm{g} / \mathrm{mL}$ PPII}

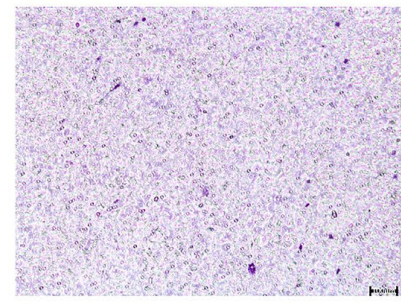

$0 \mu \mathrm{g} / \mathrm{mL}$ PPII

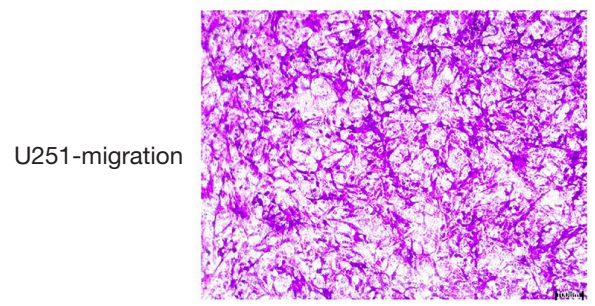

$5 \mu \mathrm{g} / \mathrm{mL}$ PPII
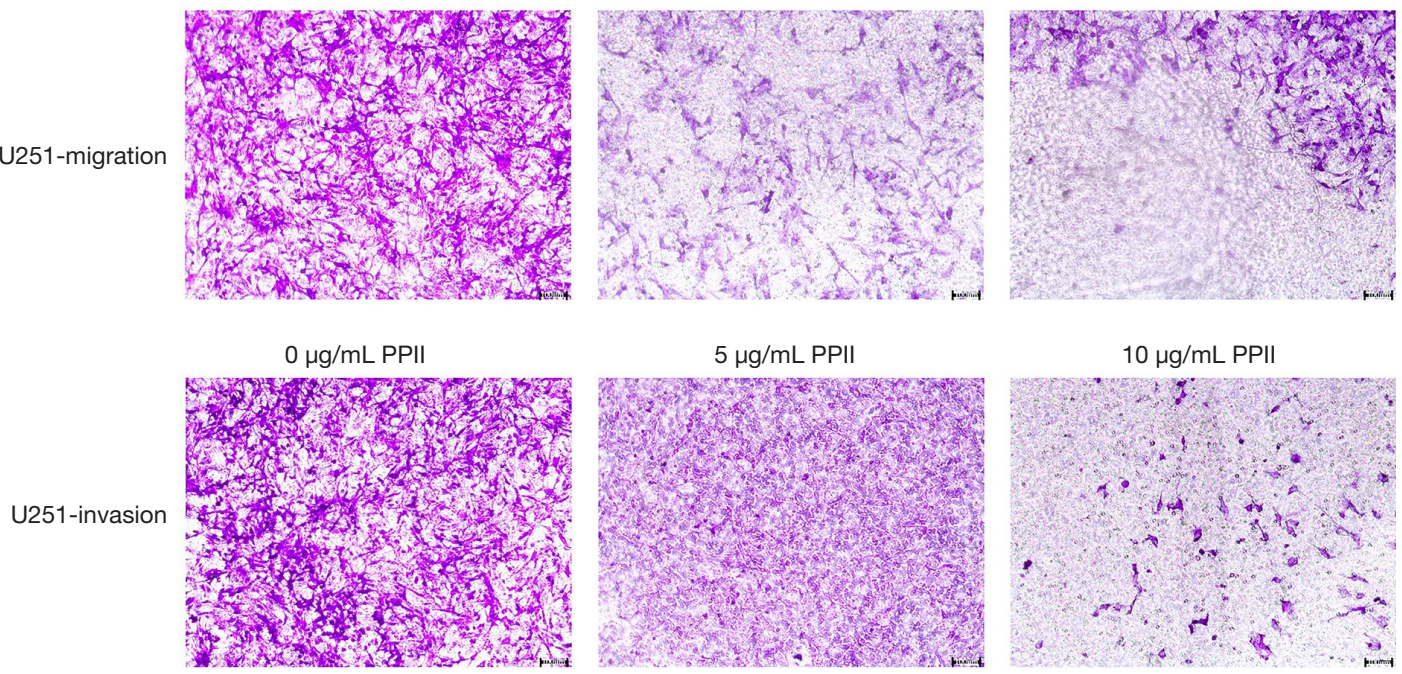

Figure 2 PPII attenuated cell clone and aggression of glioma cells. (A) PPII (Polyphyllin II) reduced the cell clone formation of U87 and U25 1 cells in a dose-dependent manner ( $n=3,14$ days, stained with $0.1 \%$ crystal violet); (B) effects of PPII attenuating migration and invasion of U87 and U251 cells ( $\mathrm{n}=3,24$ h, stained with $0.1 \%$ crystal violet). PPII, polyphyllin II. 
A

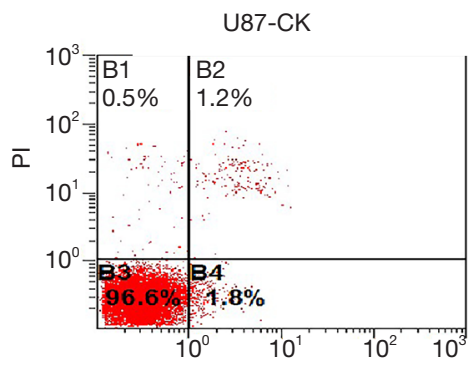

U251-CK

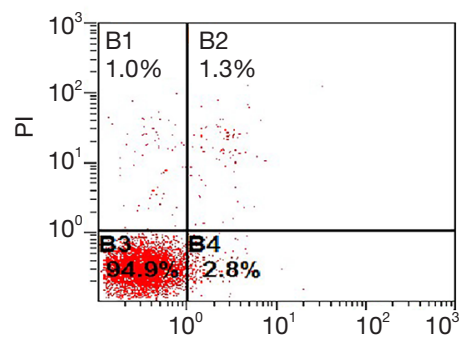

$\mathrm{U} 87+\mathrm{PPI} 1.85 \mu \mathrm{g} / \mathrm{mL}$

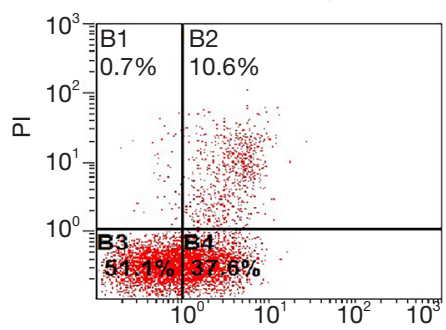

$\mathrm{U} 251+\mathrm{PPII} 5 \mu \mathrm{g} / \mathrm{mL}$

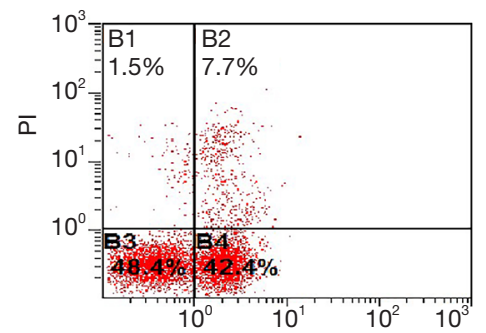

U87 + PPII $3.7 \mu \mathrm{g} / \mathrm{mL}$

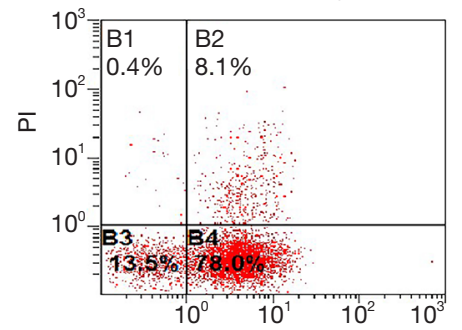

$\mathrm{U} 251+\mathrm{PPII} 10 \mu \mathrm{g} / \mathrm{mL}$

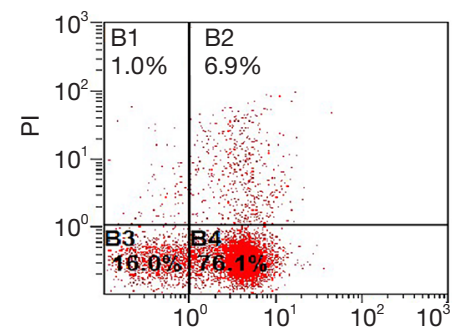

B

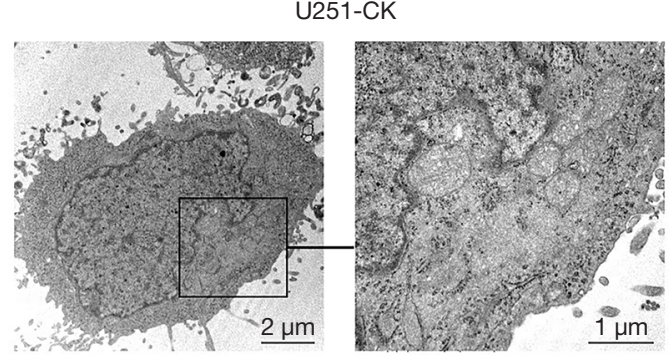

$\mathrm{U} 251+$ PPII $5 \mu \mathrm{g} / \mathrm{mL}$
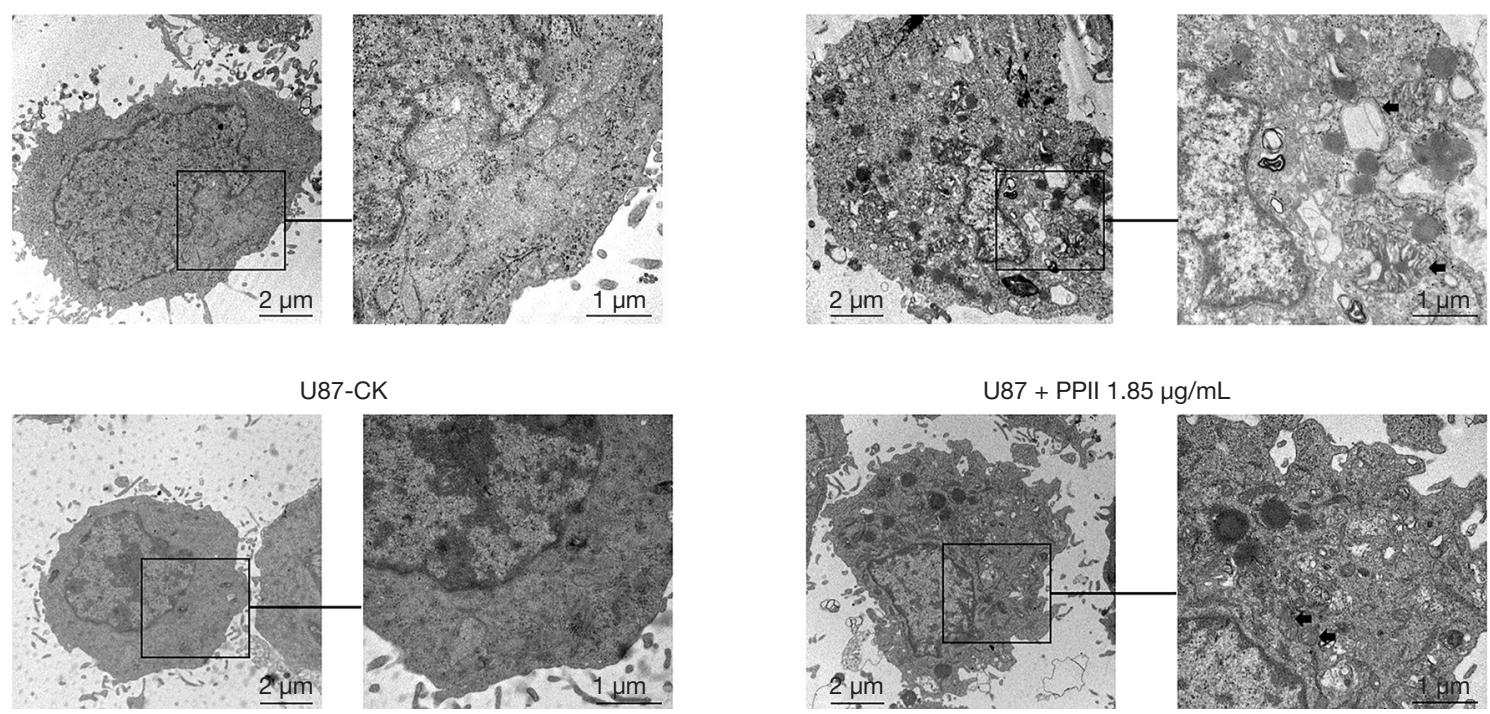

Figure 3 PPII induced apoptosis to U87 and U251 cells. (A) Both of high $(3.7 \mu \mathrm{g} / \mathrm{mL})$ and low doses $(1.85 \mu \mathrm{g} / \mathrm{mL})$ of PPII promoted the apoptosis to U87 cells, and both of high $(10 \mu \mathrm{g} / \mathrm{mL})$ and low doses $(5 \mu \mathrm{g} / \mathrm{mL})$ of PPII promoted the apoptosis to U251 cells examined by flow cytometry (n=3, 24 h); (B) TEM revealed that, normal glioma cells exhibited intact cell membranes and normal nuclei, while treated with PPII majority of cells had apoptosis features that mainly include the cytoplasmic shrinkage, the dilation of the endoplasmic reticulum, turgidity of the mitochondrion, the disarrangement, diminution and vacuolization (pointed by arrows, 24 h). PPII, polyphyllin II; TEM, transmission electron microscope.

apoptosis, three methods were performed: flow cytometry assay for apoptosis rate detection, transmission electron microscope (TEM) for observation of organelle structure change and western blot for molecular signaling pathway test. Results of flow cytometry indicated that both of high and low doses of PPII could increase the percentage of apoptotic cells. In addition, apoptosis rates were positively associated with the drug concentration (Figure 3A). Because 
A

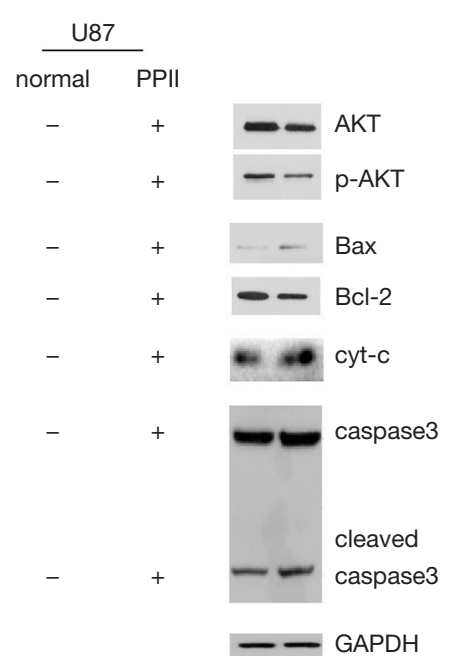

B

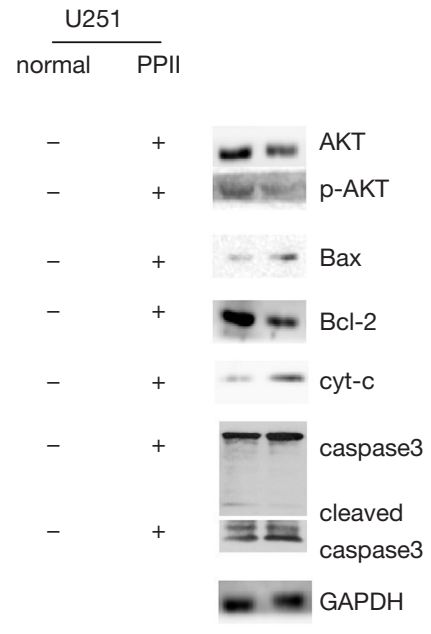

Figure 4 PPII induced mitochondrial apoptosis in U87 and U251 cells. (A) Western blot results showed $1.85 \mu \mathrm{g} / \mathrm{mL}$ PPII increased Bax, cyt-c, caspase 3 and cleaved caspase 3, and decreased AKT, p-AKT, and Bcl-2 in U87 cells, the protein level was corrected using GAPDH ( $\mathrm{n}=3$, “+” represents positive, and “-” represents negative); (B) Western blot results showed $5 \mu \mathrm{g} / \mathrm{mL}$ PPII increased Bax, cyt-c, caspase 3 and cleaved caspase 3, and decreased AKT, p-AKT, and Bcl-2 in U251 cells, the protein level was corrected using GAPDH (n=3, “+” represents positive, and “-” represents negative). PPII, polyphyllin II; Bax, BCL2-associated X protein; cyt-c, cytochrome c; AKT, protein kinase B; p-AKT, phosphorylation protein kinase B; Bcl-2, B-cell lymphoma 2; GAPDH, glyceraldehyde-3-phosphate dehydrogenase.

all the treatments led to significant apoptosis (at least over $37 \%$ ), we selected the low doses to carry on the subsequent experiments. Under TEM, majority of cells had apoptosis features that mainly include the cytoplasmic shrinkage, the dilation of the endoplasmic reticulum, turgidity of the mitochondrion, the disarrangement, diminution and vacuolization. At the same time, intact cell membrane and normal nucleus were observed in normal glioma cells (Figure 3B). That indicated PPII may induce mitochondrial apoptosis in $\mathrm{U} 87$ and $\mathrm{U} 251$ cells.

\section{PPII induced mitochondrial apoptosis in U87 and U251 cells through AKT/Bax/Bcl-2/cyt-c/caspase 3 patbway}

To determine the further molecular mechanism under PPII inducing apoptosis to glioma cells, western blot assay was used to evaluate the expression of the AKT/Bax/Bcl-2/ cyt-c/caspase 3 signaling pathway related proteins. After 24 treatments of PPII, the expressions of caspase 3, cleavedcaspase 3, Bax and cytochrome c (cyt-c) were significantly increased, and AKT, phosphorylated AKT (p-AKT) and Bcl-2 were significantly decreased in U87 and U251 (Figure 4). These results demonstrated that PPII induced mitochondrial apoptosis in U87 and U251 cells via AKT/ $\mathrm{Bax} / \mathrm{Bcl}-2 / \mathrm{cyt}-\mathrm{c} / \mathrm{caspase} 3$ pathway.

\section{ROS mediated PPII inbibition in U87 and U251 cells via Bax/cyt-c}

It was reported that natural products generated ROS to promote cancer cell apoptosis (40-44), and in the current study a rescue experiment was performed to reveal the role of ROS in PPII inhibition. With a test of concentration gradient of $\mathrm{N}$-acetyl-L-cysteine (NAC, a ROS scavenger), in U87 cells the PPII inhibition was reversed from $4 \mathrm{mg} / \mathrm{mL}$ NAC (Figure $5 A$ ), and in U251 cells the PPII inhibition was reversed from $8 \mathrm{mg} / \mathrm{mL}$ NAC by CCK-8 assays (Figure $5 B$ ). Moreover, on the molecular level, western blot showed NAC also reversed the levels of Bax and cyt-c in PPII treated $\mathrm{U} 87$ and $\mathrm{U} 251$ cells (Figure 5A,5B).

\section{Discussion}

The present study aimed to evaluate the role of PPII in the regulation of apoptosis in glioma cells, and to identify the potential underlying mechanisms. The cell proliferation was evaluated with CCK-8, cell clone formation and iCELLigence assays to verify the inhibition effect of PPII to U87 and U251 cells. The results revealed PPII significantly inhibited the cell proliferation of glioma cells in a dose- and time-dependent manner and suggested that $\mathrm{IC}_{50}$ values of 


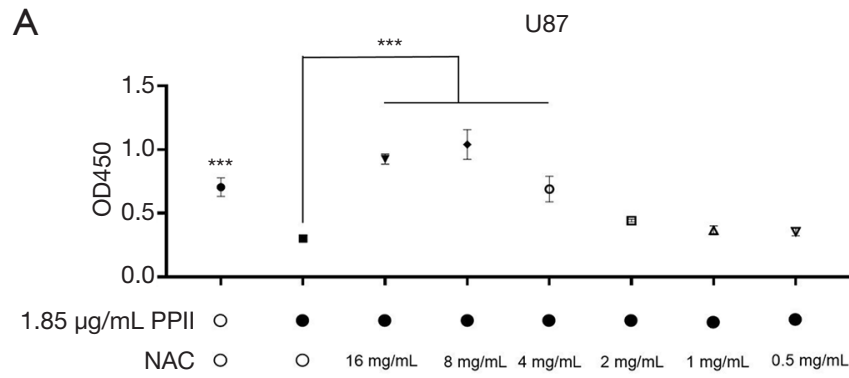

B

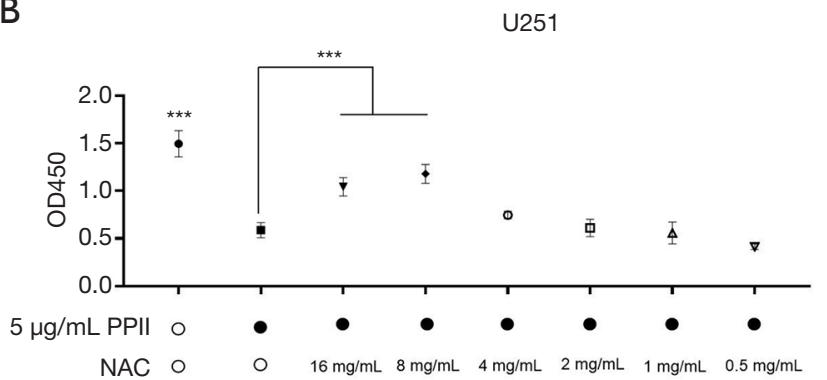

U87

$1.85 \mu \mathrm{g} / \mathrm{mL}$ PPII

$4 \mu \mathrm{g} / \mathrm{mL}$ NAC

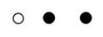

$\circ \circ \bullet$

$+-+$

$+-+$

- Bax

cyt-c

$-\cdots$ GAPDH

U251

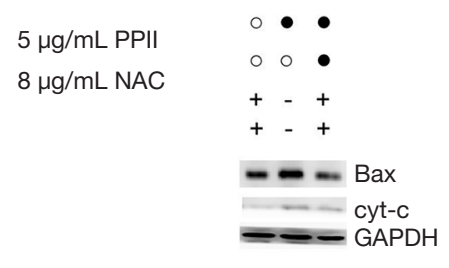

Figure 5 ROS-mediated activation of Bax and cyt-c led to inhibition in PPII-treated U87 and U251 cells. (A) CCK-8 and western blot determined that $4 \mathrm{mg} / \mathrm{mL}$ NAC was the optimal dose that could reverse the PPII inhibition via Bax and cyt-c in U87 cells, the protein level was corrected using GAPDH ( $=3$, ***, $\mathrm{P}<0.001$ compared with PPII treated U87 cell, $\circ$ means not added, • means added, “+” represents positive, and "-" represents negative); (B) CCK-8 and western blot assay determined that $8 \mathrm{mg} / \mathrm{mL}$ NAC was the optimal dose that could reverse the PPII inhibition via Bax and cyt-c in U251 cells, the protein level was corrected using GAPDH $(\mathrm{n}=3$, ***, $\mathrm{P}<0.001$ compared with PPII treated U251 cell, o means not added, • means added, “+” represents positive, and "_” represents negative). PPII, polyphyllin II; CCK8, Cell Counting Kit-8; NAC, N-acetyl-L-cysteine; Bax, BCL2-associated X protein; cyt-c, cytochrome c; GAPDH, glyceraldehyde-3phosphate dehydrogenase.

the saponin against the proliferation of U87 $(3.695 \mu \mathrm{g} / \mathrm{mL})$ and U251 (10.04 $\mu \mathrm{g} / \mathrm{mL}$ ) (Figures 1,2A). PPII was reported to suppress the migration of T98G and LN18 (although the paper title used "invasion", in that study transwell inserts were coated with nothing, thus we thought that was migration experiment) (45). In the current study, transwell results showed PPII inhibited both of migration (transwel inserts coated with nothing) and invasion (transwel inserts coated with polylysine) (Figure $2 B$ ).

From microscope observation, the cellular morphology changes and the cells become rounder after PPII treatment. After $24 \mathrm{~h}$ exposure to PPII the cells were seriously damaged: the cells became round and swollen, and the boundary was not clear. This observation suggested that PPII may induce apoptosis to the glioma cells. Therefore, flow cytometry assay and TEM were employed to confirm the suggestion. Flow cytometry assay showed PPII could induce serious apoptosis to the glioma cells at low doses (Figure $3 A$ ). TEM revealed treated with
PPII majority of cells had apoptosis features, mainly including the cytoplasmic shrinkage, the dilation of the endoplasmic reticulum, turgidity of the mitochondrion, the disarrangement, diminution, and vacuolization (Figure $3 B$ ).

The induction of apoptosis is one of the most effective approaches for treating cancer (46). Swollen mitochondrion is one of the hallmarks of early apoptosis stages in cells, since it facilitates cyt-c release in cell cytoplasm triggering intrinsic mitochondria-mediated apoptosis (47). Phosphorylation of AKT regulates Bax and Bcl-2 against apoptosis (48). Translocation of Bax to mitochondria membrane results in cyt-c release (49). Bcl-2 antagonizes Bax during the process. Caspase 3 and Bcl-2 are well-known pro- and antiapoptotic regulatory genes in eukaryotes. The Bcl-2 family controls caspase activity by inhibiting cyt-c release and subsequent caspase 3 activation (50-52). In the current study, PPII decreased levels of AKT, p-AKT and $\mathrm{Bcl}-2$, and increased cyt-c, Bax, cleaved caspase 3 and capase 3 in U87 (Figure 4A) and U251 (Figure 4B). That revealed 


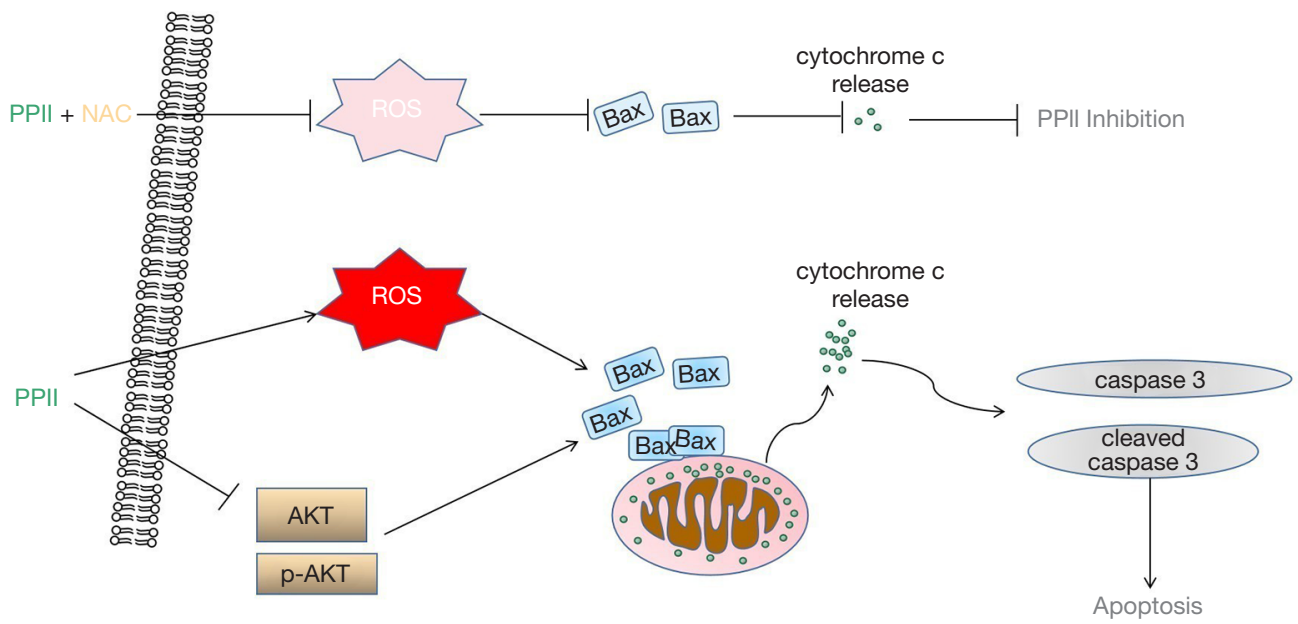

Figure 6 PPII induced apoptosis in U87 and U251 via ROS-mediated activation of Bax and cyt-c. PPII, polyphyllin II; Bax, BCL2associated X protein; cyt-c, cytochrome c.

PPII inhibited proliferation of the glioma cells may be due to inactivation of the AKT signaling pathway and activation of Bax-mediated mitochondria apoptosis.

Mitochondria is major producer of ROS, and excessively high level of ROS promotes apoptosis $(40,41)$. Previous studies reported several natural products generated ROS to activate apoptosis signaling in cancer cells. Antioxidant glutathione attenuated the piperlongumine-induced apoptosis and ROS of SKBR3, 786-O, Panc1, L3.6pL and A549 (42). A conjugate AlbA-DCA promotes ROS and killing cancer cells selectively (43). Erianin induced apoptosis to osteosarcoma in vitro and in vivo via ROS (44). In this paper NAC (a ROS scavenger) attenuated the PPII inhibition due to reversing the levels of Bax and cyt-c in PPII treated U87 (Figure 5A) and U251 (Figure 5B) cells.

In conclusion, PPII induced glioma cells mitochondrial apoptosis via ROS-mediated activation of Bax and cyt-c (Figure 6).

\section{Acknowledgments}

We would like to thank Associate Professor Wei Wang for his help in polishing our paper.

Funding: This work was supported by grants from the National Natural Science Foundation of China (No. 81973192 and 81903862), Social R\&D Program of Shaanxi Province (No. 2020SF-311, 2021SF-388 and 2021ZDLSF04-07), and the Natural Science Basic Research Plan in Shaanxi Province of China (No. 2018JM7136 and 2016JM8134).

\section{Footnote}

Reporting Checklist: The authors have completed the MDAR reporting checklist. Available at https://dx.doi. org/10.21037/tcr-21-966

Data Sharing Statement: Available at https://dx.doi. org/10.21037/tcr-21-966

Conflicts of Interest: All authors have completed the ICMJE uniform disclosure form (available at https://dx.doi. org/10.21037/tcr-21-966). The authors have no conflicts of interest to declare.

Ethical Statement: The authors are accountable for all aspects of the work in ensuring that questions related to the accuracy or integrity of any part of the work are appropriately investigated and resolved. The study was conducted in accordance with the Declaration of Helsinki (as revised in 2013). Institutional ethical approval and informed consent were waived.

Open Access Statement: This is an Open Access article distributed in accordance with the Creative Commons Attribution-NonCommercial-NoDerivs 4.0 International License (CC BY-NC-ND 4.0), which permits the noncommercial replication and distribution of the article with the strict proviso that no changes or edits are made and the original work is properly cited (including links to both the formal publication through the relevant 
DOI and the license). See: https://creativecommons.org/ licenses/by-nc-nd/4.0/.

\section{References}

1. Ostrom QT, Gittleman H, Xu J, et al. CBTRUS Statistical Report: Primary Brain and Other Central Nervous System Tumors Diagnosed in the United States in 2009-2013. Neuro Oncol 2016;18:v1-v75.

2. Seliger C, Meier CR, Becker C, et al. Statin use and risk of glioma: population-based case-control analysis. Eur J Epidemiol 2016;31:947-52.

3. Jiang H, Cui Y, Wang J, et al. Impact of epidemiological characteristics of supratentorial gliomas in adults brought about by the 2016 world health organization classification of tumors of the central nervous system. Oncotarget 2017;8:20354-61

4. Wei JC, Gao WY, Yan XD, et al. Chemical constituents of plants from the genus Paris. Chem Biodivers 2014;11:1277-97.

5. Song G, Shen X, Li S, et al. Structure-activity relationships of 3-O- $\beta$-chacotriosyl oleanane-type triterpenoids as potential H5N1 entry inhibitors. Eur J Med Chem 2016;119:109-21.

6. Xiang L, Yi X, Wang Y, et al. Antiproliferative and antiinflammatory polyhydroxylated spirostanol saponins from Tupistra chinensis. Sci Rep 2016;6:31633.

7. Khan M, Maryam A, Zhang H, et al. Killing cancer with platycodin D through multiple mechanisms. J Cell Mol Med 2016;20:389-402.

8. Tian X, Tang H, Lin H, et al. Saponins: the potential chemotherapeutic agents in pursuing new anti-glioblastoma drugs. Mini Rev Med Chem 2013;13:1709-24.

9. Lorent JH, Quetin-Leclercq J, Mingeot-Leclercq MP. The amphiphilic nature of saponins and their effects on artificial and biological membranes and potential consequences for red blood and cancer cells. Org Biomol Chem 2014;12:8803-22.

10. Wang Y, Kang W, Hong LJ, et al. Triterpenoid saponins from the root of Anemone tomentosa. J Nat Med 2013;67:70-7.

11. Zhao M, Ma N, Qiu F, et al. Triterpenoid saponins from the roots of Clematis argentilucida. Fitoterapia 2014;97:234-40.

12. Wang $\mathrm{Y}$, Tang H, Zhang Y, et al. Saponin B, a novel cytostatic compound purified from Anemone taipaiensis, induces apoptosis in a human glioblastoma cell line. Int $\mathrm{J}$
Mol Med 2013;32:1077-84.

13. Ji CC, Tang HF, Hu YY, et al. Saponin 6 derived from Anemone taipaiensis induces U87 human malignant glioblastoma cell apoptosis via regulation of Fas and $\mathrm{Bcl}-2$ family proteins. Mol Med Rep 2016;14:380-6.

14. Wang XY, Chen XL, Tang HF, et al. Cytotoxic triterpenoid saponins from the rhizomes of Anemone taipaiensis. Planta Med 2011;77:1550-4.

15. Li J, Tang H, Zhang Y, et al. Saponin 1 induces apoptosis and suppresses NF- $\mathrm{kB}$-mediated survival signaling in glioblastoma multiforme (GBM). PLoS One 2013;8:e81258.

16. Tang HF, Yun J, Lin HW, et al. Two new triterpenoid saponins cytotoxic to human glioblastoma U251MG cells from Ardisia pusilla. Chem Biodivers 2009;6:1443-52.

17. Lin $\mathrm{H}$, Zhang X, Cheng G, et al. Apoptosis induced by ardipusilloside III through BAD dephosphorylation and cleavage in human glioblastoma U251MG cells. Apoptosis 2008; 13:247-57.

18. Cheng G, Zhang X, Tang HF, et al. Asterosaponin 1 , a cytostatic compound from the starfish Culcita novaeguineae, functions by inducing apoptosis in human glioblastoma U87MG cells. J Neurooncol 2006;79:235-41.

19. Qiu PC, Lu YY, Zhang S, et al. Reduction of SCUBE3 by a new marine-derived asterosaponin leads to arrest of glioma cells in G1/S. Oncogenesis 2020;9:71.

20. Zhang SY, Yi YH, Tang HF, et al. Two new bioactive triterpene glycosides from the sea cucumber Pseudocolochirus violaceus. J Asian Nat Prod Res 2006;8:1-8.

21. Zhang SY, Tang HF, Yi YH. Cytotoxic triterpene glycosides from the sea cucumber Pseudocolochirus violaceus. Fitoterapia 2007;78:283-7.

22. Yuan WH, Yi YH, Tan RX, et al. Antifungal triterpene glycosides from the sea cucumber Holothuria (Microthele) axiloga. Planta Med 2009;75:647-53.

23. Negi JS, Bisht VK, Bhandari AK, et al. Paris polyphylla: chemical and biological prospectives. Anticancer Agents Med Chem 2014;14:833-9.

24. Qin XJ, Ni W, Chen CX, et al. Seeing the light: Shifting from wild rhizomes to extraction of active ingredients from above-ground parts of Paris polyphylla var. yunnanensis. J Ethnopharmacol 2018;224:134-9.

25. Zhang D, Li K, Sun C, et al. Anti-Cancer Effects of Paris Polyphylla Ethanol Extract by Inducing Cancer Cell Apoptosis and Cycle Arrest in Prostate Cancer Cells. Curr Urol 2018;11:144-50. 
26. Wang CW, Tai CJ, Choong CY, et al. Aqueous Extract of Paris polyphylla (AEPP) Inhibits Ovarian Cancer via Suppression of Peroxisome Proliferator-Activated Receptor-Gamma Coactivator (PGC)-1alpha. Molecules 2016;21:727.

27. Guo Y, Liu Z, Li K, et al. Paris Polyphylla-Derived Saponins Inhibit Growth of Bladder Cancer Cells by Inducing Mutant P53 Degradation While UpRegulating CDKN1A Expression. Curr Urol 2018;11:131-8.

28. Lin LT, Uen WC, Choong CY, et al. Paris Polyphylla Inhibits Colorectal Cancer Cells via Inducing Autophagy and Enhancing the Efficacy of Chemotherapeutic Drug Doxorubicin. Molecules 2019;24:2102.

29. Liu J, Zhang Y, Chen L, et al. Polyphyllin I induces G2/M phase arrest and apoptosis in U251 human glioma cells via mitochondrial dysfunction and the JNK signaling pathway. Acta Biochim Biophys Sin (Shanghai) 2017;49:479-86.

30. Tian Y, Gong GY, Ma LL, et al. Anti-cancer effects of Polyphyllin I: An update in 5 years. Chem Biol Interact 2020;316:108936.

31. Pang D, Yang C, Li C, et al. Polyphyllin II inhibits liver cancer cell proliferation, migration and invasion through downregulated cofilin activity and the AKT/NF- $\mathrm{B}$ pathway. Biol Open 2020;9:bio046854.

32. Niu W, Xu L, Li J, et al. Polyphyllin II inhibits human bladder cancer migration and invasion by regulating EMT-associated factors and MMPs. Oncol Lett 2020;20:2928-36.

33. Pang D, Li C, Yang C, et al. Polyphyllin VII Promotes Apoptosis and Autophagic Cell Death via ROSInhibited AKT Activity, and Sensitizes Glioma Cells to Temozolomide. Oxid Med Cell Longev 2019;2019:1805635.

34. Lin Z, Liu Y, Li F, et al. Anti-lung Cancer Effects of Polyphyllin VI and VII Potentially Correlate with Apoptosis In Vitro and In Vivo. Phytother Res 2015;29:1568-76.

35. Song C, Pan B, Yang X, et al. Polyphyllin VII suppresses cell proliferation, the cell cycle and cell migration in colorectal cancer. Oncol Lett 2021;21:25.

36. He DX, Li GH, Gu XT, et al. A new agent developed by biotransformation of polyphyllin VII inhibits chemoresistance in breast cancer. Oncotarget 2016;7:31814-24.

37. Zhao L, Liu Z, Deng X, et al. Polyphyllin VII induces mitochondrial apoptosis by regulating the PP2A/AKT/
DRP1 signaling axis in human ovarian cancer. Oncol Rep 2021;45:513-22.

38. Committee CP. China Pharmacopoeia. Beijing: The Medicine Science and Technology Press of China, 2020;1:271.

39. Que Z, Wang P, Hu Y, et al. Dihydroartemisin inhibits glioma invasiveness via a ROS to P53 to $\beta$-catenin signaling. Pharmacol Res 2017;119:72-88.

40. Santos RX, Correia SC, Zhu X, et al. Mitochondrial DNA oxidative damage and repair in aging and Alzheimer's disease. Antioxid Redox Signal 2013;18:2444-57.

41. Zhou S, Wen H, Li H. Magnolol induces apoptosis in osteosarcoma cells via G0/G1 phase arrest and p53mediated mitochondrial pathway. J Cell Biochem 2019;120:17067-79.

42. Karki K, Hedrick E, Kasiappan R, et al. Piperlongumine Induces Reactive Oxygen Species (ROS)-Dependent Downregulation of Specificity Protein Transcription Factors. Cancer Prev Res (Phila) 2017;10:467-77.

43. Wei G, Sun J, Luan W, et al. Natural Product Albiziabioside A Conjugated with Pyruvate Dehydrogenase Kinase Inhibitor Dichloroacetate To Induce ApoptosisFerroptosis-M2-TAMs Polarization for Combined Cancer Therapy. J Med Chem 2019;62:8760-72.

44. Wang H, Zhang T, Sun W, et al. Erianin induces G2/ M-phase arrest, apoptosis, and autophagy via the ROS/ JNK signaling pathway in human osteosarcoma cells in vitro and in vivo. Cell Death Dis 2016;7:e2247.

45. Zhao YP, Duan WC, Wang YM, et al. Effect of polyphyllin II on the proliferation, invasion and chemosensitivity to temozolomide of glioma cells. Zhonghua Yi Xue Za Zhi 2020;100:2774-8.

46. Zhou D, Qu Z, Wang H, et al. The effect of hydroxy safflower yellow A on coronary heart disease through Bcl2/Bax and PPAR- $\gamma$. Exp Ther Med 2018;15:520-6.

47. Yefimova MG, Buschiazzo A, Burel A, et al. Autophagy is increased in cryptorchid testis resulting in abnormal spermatozoa. Asian J Androl 2019;21:570-6.

48. Chu L, Xiao L, Xu B, et al. Dissociation of HKII in retinal epithelial cells induces oxidative stress injury in the retina. Int J Mol Med 2019;44:1377-87.

49. Chintamani, Kulshreshtha P, Chakraborty A, et al. Androgen receptor status predicts response to chemotherapy, not risk of breast cancer in Indian women. World J Surg Oncol 2010;8:64.

50. Griffiths GS, Doe J, Jijiwa M, et al. Bit-1 is an essential regulator of myogenic differentiation. J Cell Sci 2015;128:1707-17. 
51. Condorelli G, Roncarati R, Ross J Jr, et al. Heart-targeted overexpression of caspase 3 in mice increases infarct size and depresses cardiac function. Proc Natl Acad Sci U S A 2001;98:9977-82.

Cite this article as: Cheng G, Xue YY, Fang F, Sun GQ, Lu YY, Ji YQ, Qiu PC, Tang HF. Promotion of Ros-mediated Bax/Cyt-c apoptosis by polyphyllin II leads to suppress growth and aggression of glioma cells. Transl Cancer Res 2021;10(9): 3894-3905. doi: 10.21037/tcr-21-966
52. Rao M, Chen D, Zhan P, et al. MDA19, a novel CB2 agonist, inhibits hepatocellular carcinoma partly through inactivation of AKT signaling pathway. Biol Direct 2019;14:9. 